\title{
Influence of Steel Surface Composition on ZDDP Tribofilm Growth Using Ion Implantation
}

\author{
Mao Ueda ${ }^{1}$ (D) Amir Kadiric ${ }^{1} \cdot$ Hugh Spikes ${ }^{1}$
}

Received: 16 February 2021 / Accepted: 1 April 2021 / Published online: 23 April 2021

(c) The Author(s) 2021

\begin{abstract}
This paper examines the influence of steel surface composition on antiwear tribofilm formation by ion-implanting typical steel alloying elements, Ni, Mo, Cr, V and W, into AISI 52100 bearing steel surfaces. Such implantation changes the chemical composition of the steel surface but has relatively little effect on its mechanical properties or topography. The behaviour of zinc dialkyldithiophosphate (ZDDP) antiwear additive was studied. The study employs a ball on disc tribometer with ability to monitor tribofilm development and a range of analytical tools including STEM-EDX, XPS and FIB-TEM to analyse the formed tribofilms. It was found that $\mathrm{Ni}$ implantation promotes ZDDP tribofilm formation while Mo and Cr implantation deters tribofilm growth. $\mathrm{V}$ and $\mathrm{W}$ implantation do not significantly change tribofilm formation. Results on the influence of ZDDP concentration on tribofilm formation rate with different implanted metals suggest that one important mechanism by which steel composition influences tribofilm formation may be by controlling the extent of ZDDP adsorption. This study shows the importance of steel surface composition on ZDDP response and also demonstrates a powerful way to study and potentially improve the tribological performance of machine components via a combination of lubricant formulation and surface modification.
\end{abstract}

Keywords Ion implantation $\cdot$ ZDDP $\cdot$ Tribofilm $\cdot$ Adsorption $\cdot$ Wear $\cdot \mathrm{Ni} \cdot \mathrm{Mo} \cdot \mathrm{Cr}$

\section{Introduction}

In recent years the role of lubricant antiwear additives, especially ZDDPs, has become increasingly important because of the introduction of very low viscosity oils to reduce power losses from hydrodynamic friction, churning and pumping, and thus increase machine efficiency. Such low viscosity oils can result in the machine components operating for long periods in thin film, mixed lubrication conditions. Under these conditions, wear of rubbing surfaces is likely to occur. Therefore, it has become increasingly important to understand the ability of ZDDP, to form antiwear tribofilms and thereby protect rubbing surfaces.

Effective tribofilm formation relies on the interaction of ZDDP with a rubbing, solid surface, and to understand and improve the anti-wear performance, it is essential to consider the additive and surface in combination. Previous

Mao Ueda

m.ueda18@imperial.ac.uk

1 Imperial College London, Tribology Group, London SW7 2AZ, UK investigations have shown that ZDDP tribofilm formation is affected by the solid surface properties, including hardness [1-3] and roughness [4-6], as well as chemical composition $[7,8]$. All these surface properties must be taken into account when studying mechanisms of tribofilm formation. Of these, the least well understood is the influence of chemical composition since it is quite difficult to vary this independently of hardness and roughness.

Pagkalis et al. [8] have recently shown that the growth and performance of antiwear tribofilms are different on steel types. In the case of ZDDP, the rate of tribofilm formation was slower on AISI M2 steel than on AISI 52100, $16 \mathrm{MnCr} 5$ and 440C steels. Jelita Rydel et al. [7] found that thinner ZDDP tribofilms formed locally on residual carbides than on the surrounding martensite matrix of steels. From the above, it appears that steel composition, including the presence of different non-ferrous metals in steels, may play a role in antiwear tribofilm formation. One approach to studying these effects in a controlled manner, might be to examine the formation of ZDDP tribofilms on a range of non-ferrous metals. However, a problem that arises is that different metals have very different hardnesses and hardness itself 
influences tribofilm formation. For example, Gosvami et al. [9] found that sliding promoted strain-hardening of $\mathrm{Al}$ with the counterface of $\mathrm{Al}_{2} \mathrm{O}_{3}$ in a ZDDP solution, resulting in ZDDP tribofilm formation on the hardened surface. This makes it difficult to isolate the effect of the relevant metal on ZDDP tribofilm formation. An alternative approach would be to manufacture a range of steels with systematicallyvaried alloying elements and prepare from these suitable tribological test specimens. Unfortunately, this is currently impractical in terms of cost, especially when ball specimens are needed. The use of specimens with a thin coating of the metal of interest on steel substrate is also problematic as such coatings often cannot survive the contact conditions imposed in typical sliding-rolling tribological tests [19].

The approach adopted in this study is to investigate the impact of alloying elements in steel on antiwear performance using ion implantation to dope surfaces of steel specimens with a series of non-ferrous metallic elements. This has the advantage of causing relatively little change in roughness from the original surface and not altering the dimensions of the original sample, although, depending on the implanted element, it may increase the hardness. Another practical advantage is that it can be used as easily on steel balls as on flats, so enabling rolling-sliding tests to be carried out with materials not generally available in ball form.

Ion implantation to steel has been studied and applied quite extensively to control friction, wear and corrosion performance. Ions can be implanted up to a few nm to $\mu \mathrm{m}$ depending on implantation conditions [10-13]. Most ion implantation research in tribology has studied the effect of implanting non-metallic elements, particularly N, but also $\mathrm{C}$ and $\mathrm{B}$, with the aim of improving the physical properties of the rubbing surfaces. While the effect of ion implantation on hardness of surfaces is dependent on the type of ions, non-metallic elements such as $\mathrm{N}$ and $\mathrm{B}$ are likely to harden surfaces by forming ceramic compounds, for example $\mathrm{CrN}$, or interstitials, resulting in the improvement of wear performance $[10,14]$.

Very few researchers have studied the effect of ion implantation on tribofilm formation. Yang et al. [15-17] showed $\mathrm{Ni}, \mathrm{Mo}$ and $\mathrm{Al}$ implantation in pure iron deterred the formation of ZDDP tribofilms. However, ion implantation into pure iron might have caused lattice distortion of iron, which could create residual compressive stresses and hence increase hardness of the near substrate region [18]; this means that both chemical and mechanical properties of the surfaces were potentially changed. More recently, Pagkalis [19] studied the effect of ion implantation of AISI 52100 steel on ashless dithiophosphate additive tribofilm growth, and found that some ashless tribofilms can form faster and reach higher thickness on $\mathrm{Ni}$-implanted steel discs than on unimplanted steel, while $\mathrm{Cr}$-implantation deterred tribofilm growth. Pagkalis did not study the behaviour of ZDDP on ion-implanted surfaces and effect of chemical composition of steel on ZDDP tribofilm formation is not yet well understood.

The aim of this study is to apply ion implantation in steel to systematically investigate the effect of a series of alloying metals commonly present in steels used in tribological components on ZDDP tribofilm formation and the chemical properties of formed tribofilms. Possible mechanisms by which implanted metals affect ZDDP tribofilm growth are then suggested based on tribofilm analysis using STEMEDX, XPS and TEM.

\section{Test Materials}

\subsection{Test Lubricants}

A solution of ZDDP in a polyalphaolefin (PAO) base oil was studied. The base oil was PAO 4 having viscosity 18.5 $\mathrm{mm}^{2} / \mathrm{s}$ at $40{ }^{\circ} \mathrm{C}$ and $4.1 \mathrm{~mm}^{2} / \mathrm{s}$ at $100^{\circ} \mathrm{C}$. The secondary $\mathrm{C} 6$ ZDDP was used at a concentration of $800 \mathrm{ppm}$ P. Selected tests were performed at ZDDP concentrations of 200, 400 and $1600 \mathrm{ppm}$; this is indicated in the relevant figures as necessary.

\subsection{MTM Test Specimens}

Standard and ion-implanted AISI 52100 steel discs and balls were studied. In all tests the ball and disc were made of the same material. The following metals were implanted in steel discs and balls; nickel (Ni), molybdenum (Mo), chromium $(\mathrm{Cr})$, vanadium $(\mathrm{V})$ and tungsten $(\mathrm{W})$. A metal vapor vacuum arc (MEVVA) ion source was used to generate ions. Doses of ions were $3 \times 10^{17}$ ions $/ \mathrm{cm}^{2}$ with an extraction voltage of $45 \mathrm{kV}$. These implanted metals were chosen as they are present in many steels that are widely used for tribological components including case-carburising gear steels, stainless steels, high speed steels and bearing steels, including aerospace grades M50 and M50NiL.

\subsubsection{Mechanical Properties of Disc and Ball Specimens}

Table 1 shows roughness values of the implanted balls and discs measured using a stylus profilometer. Also shown are specimen hardness values measured using a standard Vickers indenter. In all cases the values shown in the table are the average of at least four measurements in different locations on each specimen, and tolerances show variation of measurements. Vickers Hardness values were measured using $1 \mathrm{~N}$ force, corresponding to approximately $7 \mu \mathrm{m}$ of indentation depth. Since ion-implanted depth is $c a .50 \mathrm{~nm}$ (see Fig. 2), these hardness values reflect the hardness of the bulk, implant-free steel. 
Table 1 Measured properties of MTM discs and balls

\begin{tabular}{llll}
\hline Material & & $\begin{array}{l}\text { Surface roughness } \\
\text { Rq }(\mathrm{nm})\end{array}$ & $\begin{array}{l}\text { Vickers } \\
\text { hardness } \\
(\mathrm{HV})\end{array}$ \\
\hline AISI 52100 steel & Disc & $9 \pm 3$ & $730 \pm 30$ \\
& Ball & $7 \pm 2$ & $820 \pm 30$ \\
Ni-implanted & Disc & $8 \pm 3$ & $750 \pm 25$ \\
& Ball & $7 \pm 2$ & $810 \pm 30$ \\
Mo-implanted & Disc & $10 \pm 3$ & $715 \pm 5$ \\
Cr-implanted & Ball & $8 \pm 3$ & $800 \pm 30$ \\
& Disc & $9 \pm 3$ & $700 \pm 5$ \\
V-implanted & Ball & $6 \pm 2$ & $810 \pm 30$ \\
W-implanted & Disc & $7 \pm 2$ & $720 \pm 10$ \\
& Ball & $8 \pm 3$ & $840 \pm 40$ \\
& Disc & $10 \pm 3$ & $740 \pm 20$ \\
& Ball & $7 \pm 2$ & $830 \pm 30$ \\
\hline
\end{tabular}

To determine the effect of ion implantation on hardness close to the surface, and thus relevant to tribological behaviour and tribofilm formation, nano-scale depth profiles of hardness of the ion-implanted steel discs were measured using nanoindentation and employing the continuous stiffness measurement (CSM) method. Details of the test method are given in Sect. 3.4. Figure 1a shows the hardness depth
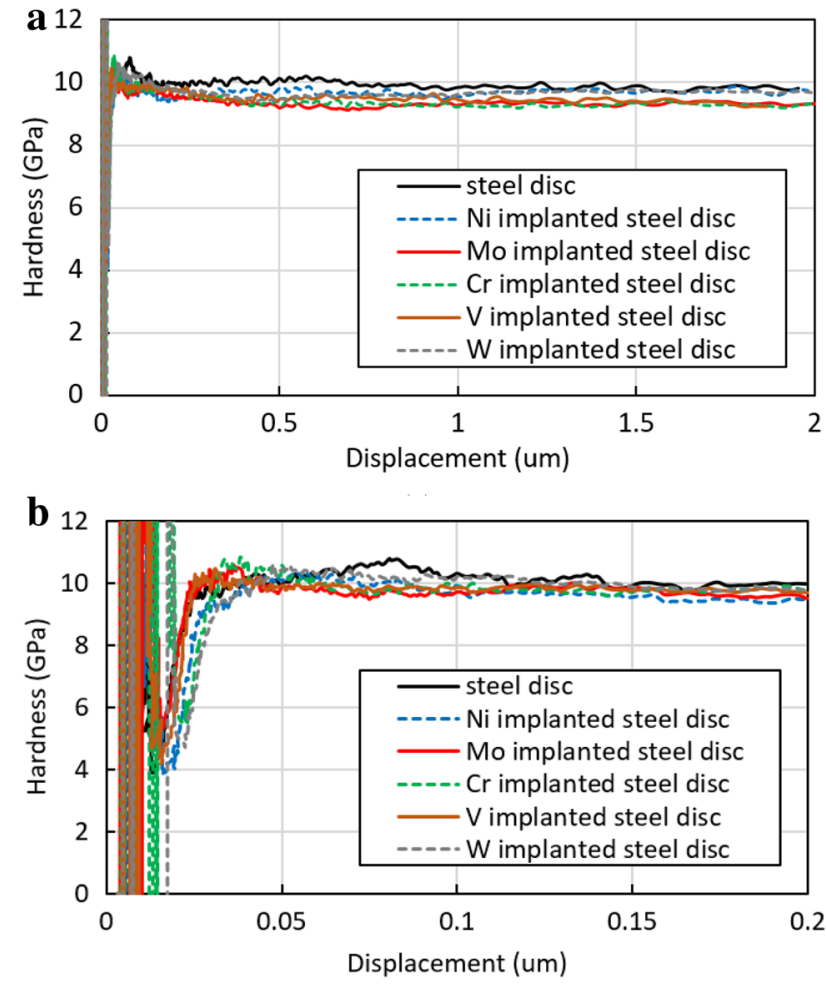

Fig. 1 Depth profile of nano-indentation hardness of ion-implanted steels a up to $2 \mu \mathrm{m}$ and $\mathbf{b}$ up to $0.2 \mu \mathrm{m}$ profiles over the $2 \mu \mathrm{m}$ target depth and Fig. 1b shows the profile in the enlarged area up to $0.2 \mu \mathrm{m}$. Generally, the true mechanical properties of surface-treated materials can only be determined from indentation data originating from the outermost $10 \%$ of the surface treatment because of the wellknown substrate effect [20]. Since implanted ion penetration depth is about $50 \mathrm{~nm}$ as shown in Fig. 2, hardness values should be obtained in the range of less than $5 \mathrm{~nm}$ from the surfaces. Unfortunately, as illustrated in Fig. 1b, hardness profiles below $0.05 \mu \mathrm{m}$ are unstable due to an indentation size effect. Therefore, the outermost surface hardness of implanted discs could not be measured.

\subsubsection{Chemical Composition of Disc and Ball Specimens}

Table 2 shows the chemical composition of the specimens measured by scanning electron microscopy and energy-dispersive X-ray spectroscopy (SEM-EDX). An SEM was used to capture high-resolution images of tribofilm surface topography and for EDX, an Oxford Instruments X-ray System INCA was employed to analyse the chemical composition of the specimens. Ion implantation increased the concentration of implanted ions in the discs and balls by approximately 1.5 at. $\%$ and 1.3 at. $\%$, respectively. To determine the penetration depth of ions, the depth profile of elemental distribution in an unrubbed Ni-implanted steel disc and a rubbed
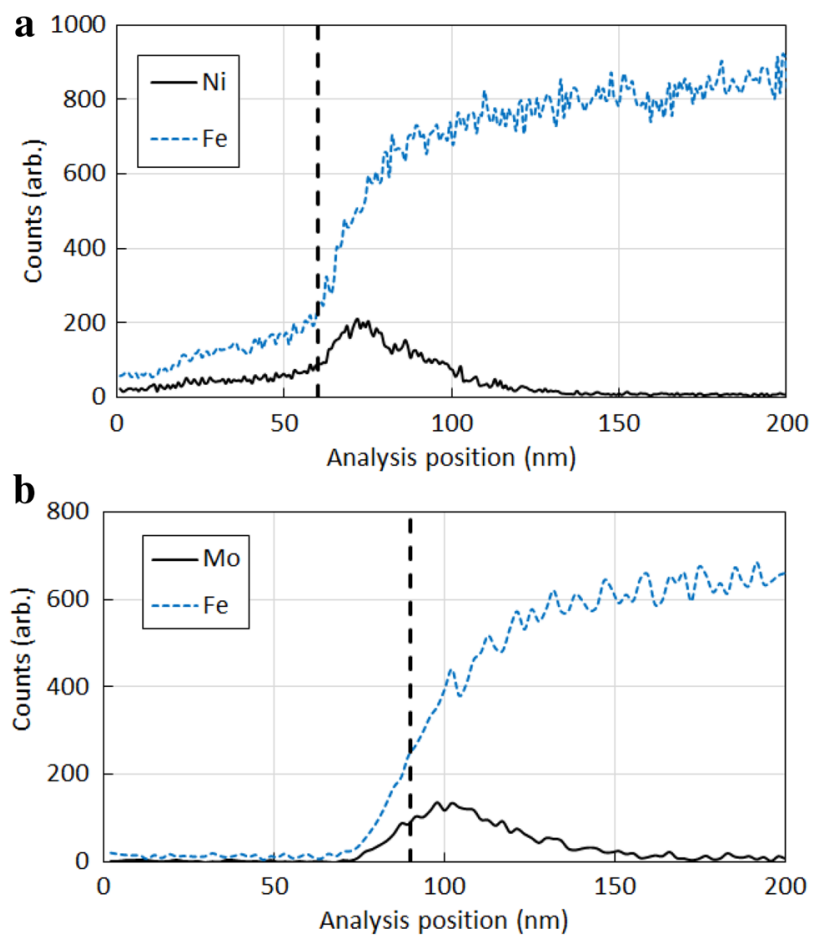

Fig. 2 STEM-EDX analysis of a cross section of a an unrubbed Niimplanted disc and $\mathbf{b}$ rubbed Mo-implanted disc in ZDDP solution. Approximate position of each surface is marked with a dashed line 
Table 2 Measured chemical composition of MTM discs and balls (at.\%)

\begin{tabular}{llllllllll}
\hline Material & & $\mathrm{Fe}$ & $\mathrm{Mn}$ & $\mathrm{Si}$ & $\mathrm{Cr}$ & $\mathrm{Ni}$ & $\mathrm{Mo}$ & $\mathrm{V}$ & $\mathrm{W}$ \\
\hline \multirow{2}{*}{ AISI 52100 steel } & Disc & 96.4 & 0.7 & 0.8 & 2.1 & & & \\
& Ball & 96.4 & 0.6 & 1.1 & 1.9 & & & \\
Ni-implanted & Disc & 95.1 & 0.6 & 0.8 & 2.0 & 1.5 & & \\
Mo-implanted & Ball & 95.4 & 0.7 & 1.0 & 1.7 & 1.2 & & \\
& Disc & 95.3 & 0.7 & 0.8 & 1.6 & & 1.6 & \\
Cr-implanted & Ball & 95.5 & 0.7 & 1.0 & 1.5 & & 1.3 & \\
& Disc & 95.0 & 0.7 & 0.8 & 3.5 & & & \\
V-implanted & Ball & 95.0 & 0.8 & 1.0 & 3.2 & & & & \\
& Disc & 94.6 & 0.8 & 0.9 & 2.2 & & & 1.5 & \\
W-implanted & Ball & 94.7 & 0.8 & 1.1 & 2.1 & & & & \\
& Disc & 94.7 & 0.7 & 1.2 & 1.9 & & & & 1.5 \\
& Ball & 95.0 & 0.7 & 1.1 & 1.9 & & & & 1.3 \\
\hline
\end{tabular}

Mo-implanted steel disc in ZDDP solution were measured using STEM-EDX as shown Fig. 2. These indicate that implanted metal is distributed within $40-60 \mathrm{~nm}$ of the surface, with a maximum implanted metal-iron ratio of about $30 \%$. It should be noted that the distributions appear to have a maximum slightly beneath the surface, but this is believed to be an artefact from the finite width resolution of the measurement method due to the size of the X-ray excitation volume in the lamellae [21]. In fact, the maximum implanted metal concentration is believed to be at or very close to the surface, with a roughly exponential decay into the bulk. To determine the chemical state of ions at the surface, Ni-, Mo-, Cr-, V-, W-implanted discs were analysed by XPS as shown Fig. 3. The detailed procedure and conditions are described in 3.3.2. From the peak areas, $\mathrm{Ni}, \mathrm{Mo}, \mathrm{Cr}, \mathrm{V}$, and $\mathrm{W}$ on steel discs are mainly present as metal and the oxides $\mathrm{NiO}, \mathrm{MoO}_{3}$ $\mathrm{Cr}_{2} \mathrm{O}_{3}, \mathrm{~V}_{2} \mathrm{O}_{5}$, and $\mathrm{WO}_{3}$ respectively [22-26]. Table 3 lists the surface compositions based on XPS and indicates that the ratio of implanted metal ions to iron at the surface was between 10 and $30 \%$. This is consistent with the maximum ratios shown in Fig. 2.

\section{Test Methods}

\subsection{MTM Test Rig}

A mini-traction machine (MTM) ball on disc tribometer with a spacer layer imaging attachment (SLIM) was employed to observe ZDDP tribofilm growth. A schematic of the rig is shown in Fig. 4. A 19.05-mm-diameter ball is loaded against the flat surface of a 46-mm-diameter-disc which is immersed in the test lubricant. The ball and the disc are driven by separate electric motors at specified rolling/sliding conditions. To capture SLIM images, the rubbing test is paused and the ball is raised and loaded against a glass flat. The glass flat surface is coated with a semi-reflective chromium layer on top of which is a transparent silica spacer layer. Light waves reflected from the chromium layer and the ball surface undergo optical interference upon recombination, generating an interference image of the contact between the ball and the glass surface which is then captured by an RGB camera. Tribofilm thickness is determined from this interferometry image using calibrated RGB values.

\subsection{Test Conditions and Procedures}

The contact conditions used in the MTM-SLIM tests are shown in Table 4 . These are the same conditions as used by Pagkalis et al. [8, 19] other than the shorter test duration of $4 \mathrm{~h}$ instead of $12 \mathrm{~h}$. Under these conditions, the lambda ratio (ratio of EHD film thickness to composite surface roughness) was calculated to be 0.1 , thus these rubbing conditions were in the boundary lubrication regime. The development of ZDDP tribofilm on balls was monitored by SLIM measurements performed at set intervals throughout the $4 \mathrm{~h}$ test. All tests shown in this paper were repeated twice and the differences of tribofilm thickness and friction coefficient between repeat tests were always less than $10 \%$. The values plotted on the relevant graphs are representative value obtained from one result.

\subsection{Tribofilm Analysis}

At the end of the 4-h rubbing test, tribofilms on the discs were analysed using XPS, TEM and STEM-EDX. Before analysis, discs were lightly rinsed in toluene without any wiping, to remove supernatant liquid but avoid removing tribofilm from the surfaces.

\subsubsection{Tribofilm Elemental Distribution and Crystallinity (TEM and STEM-EDX)}

To investigate the elemental distribution and crystallinity of fresh ion-implanted discs and formed tribofilms, lamellae of relevant specimen cross sections extracted 

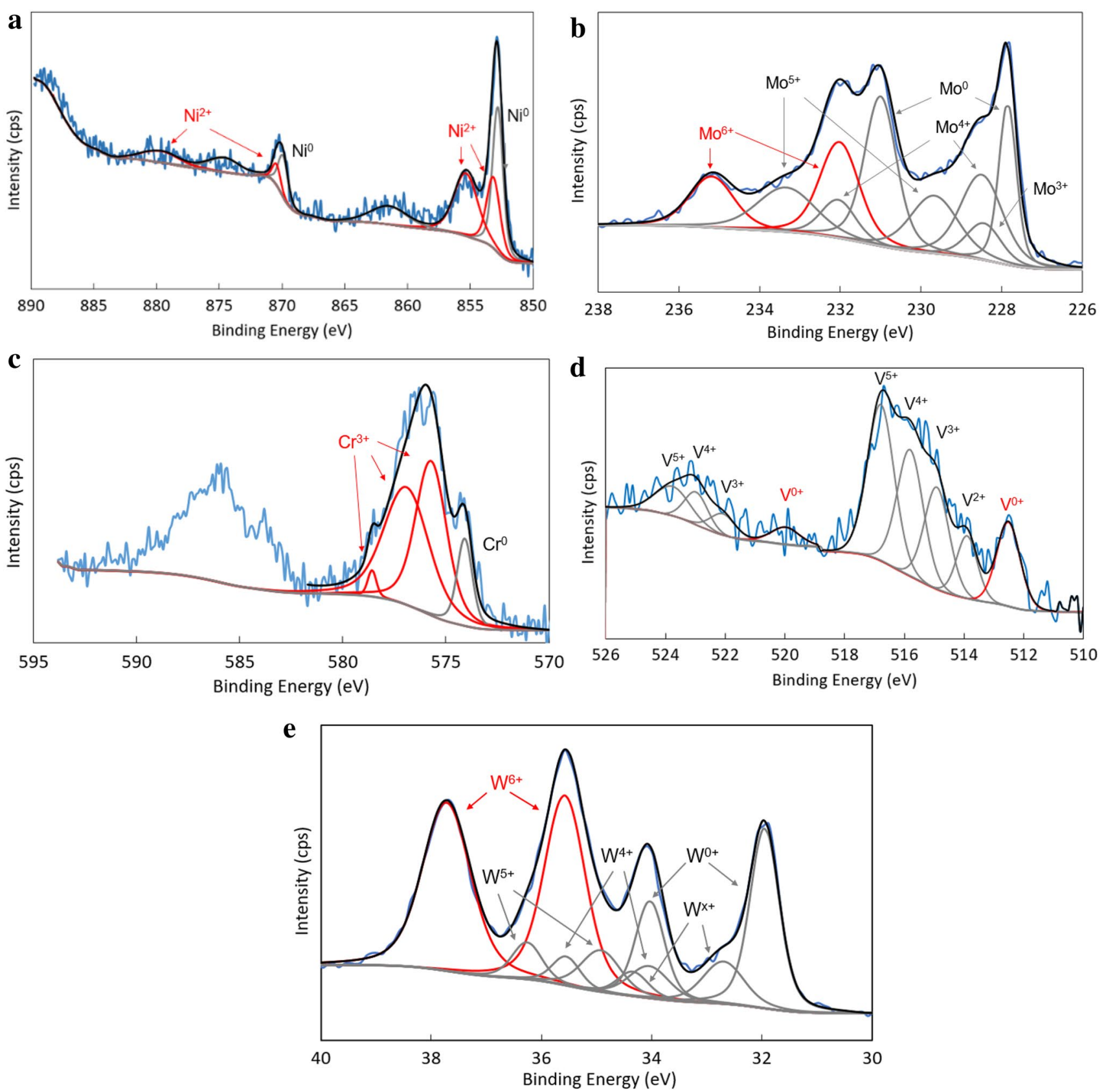

Fig. 3 Example XPS spectra of a Ni-, b Mo-, c Cr-, d V-, e W-implanted disc

using a Helios 600 NanoLab Focused Ion Beam (FIB) instrument were studied using Scanning Transmission Electron Microscopy Energy-Dispersive X-ray spectroscopy (STEM-EDX) and transmission electron microscopy (TEM). Before FIB preparation, the ZDDP tribofilms were coated with a $50-70 \mathrm{~nm} \mathrm{Cr}$ layer to protect them from damage during gallium ion milling [26, 27]. Table 5 shows the conditions used in the FIB process. After coating in $\mathrm{Cr}$, the specimens were installed in a vacuum chamber and a $\mathrm{Pt}$ layer was deposited in an atmosphere of Ga. After bulk-out and U-cut milling processes using Ga ions, lamellae with tribofilm (width: $10 \mu \mathrm{m}$, depth: $7 \mu \mathrm{m}$, thickness: $100 \mathrm{~nm}$ ) were lifted out using a tungsten omniprobe. These lamellae were then mounted on copper grids and thinned down and cleaned. STEM and TEM were performed on a JEOL-2100 $\mathrm{F}$ operated at $200 \mathrm{kV}$, equipped with an Oxford Instruments EDX detector. Elemental maps of tribofilm were collected on the samples tilted to $15^{\circ}$ using the Oxford Instruments X-ray System INCA. To confirm the implantation of ions into steel, elemental distributions of unused ion-implanted discs were also obtained as shown in Fig. 2. Before FIB preparation, the unrubbed ion-implanted discs 
Table 3 Chemical composition of MTM discs using XPS (at.\%)

\begin{tabular}{|c|c|c|c|c|c|}
\hline$\overline{\text { At. } \%}$ & Cr-implanted & Mo-implanted & Ni-implanted & V-implanted & W-implanted \\
\hline $\mathrm{C} 1 \mathrm{~s}$ & 45.17 & 33.83 & 40.97 & 39.76 & 38.46 \\
\hline $\mathrm{N} 1 \mathrm{~s}$ & 1.97 & & 2.01 & & \\
\hline $\mathrm{O} 1 \mathrm{~s}$ & 41.7 & 48.22 & 44.67 & 47.06 & 41.5 \\
\hline $\mathrm{Fe} 2 \mathrm{p}$ & 9.06 & 13.72 & 10.21 & 11.67 & 16.8 \\
\hline $\mathrm{Ni} 2 \mathrm{p}$ & & & 2.14 & & \\
\hline Mo 3d & & 4.23 & & & \\
\hline $\operatorname{Cr} 2 p$ & 2.10 & & & & \\
\hline V $2 p$ & & & & 1.51 & \\
\hline $\mathrm{W} 4 \mathrm{f}$ & & & & & 3.24 \\
\hline $\begin{array}{l}\text { Implanted } \\
\text { ion:Fe ratio }\end{array}$ & 0.23 & 0.31 & 0.21 & 0.13 & 0.19 \\
\hline
\end{tabular}

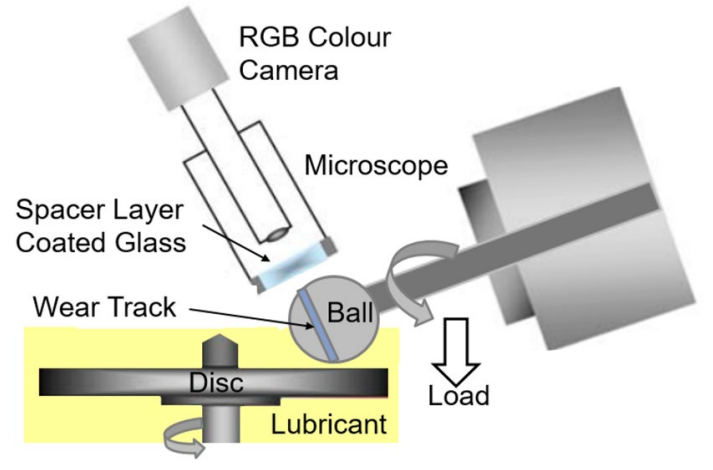

Fig. 4 Schematic image of the MTM-SLIM set-up

were coated with a $50-70 \mathrm{~nm} \mathrm{Au}$ layer, not $\mathrm{Cr}$ as was the case for ZDDP tribofilms, to protect them from damage during gallium ion milling and to avoid peak overlapping between $\mathrm{Cr}$ and targeted ions.

\subsubsection{Tribofilm Chemical Characterization (XPS)}

A Thermo Fisher K-Alpha spectrophotometer was used for X-ray photoelectron spectroscopy (XPS) to analyse the chemical structure of ZDDP tribofilms on ionimplanted steels. A monochromatic Al-K $\alpha \mathrm{X}$-ray source
Table 5 Focused ion beam conditions for ZDDP tribofilm cross section preparation

\begin{tabular}{lll}
\hline Step & $\begin{array}{l}\text { Acceleration } \\
\text { voltage }\end{array}$ & Beam current \\
\hline Pt deposition & $30 \mathrm{kV}$ & $0.46 \mathrm{nA}$ \\
Bulk-out & $30 \mathrm{kV}$ & $21 \mathrm{nA}$ \\
Cleaning of cross section & $30 \mathrm{kV}$ & $6.5 \mathrm{nA}$ \\
U-cut & $30 \mathrm{kV}$ & $6.5 \mathrm{nA}$ \\
Thinning & $30 \mathrm{kV}$ & $0.46 \mathrm{nA}$ \\
Cleaning & $2 \mathrm{kV}$ & $28 \mathrm{pA}$ \\
\hline
\end{tabular}

$($ energy $=1486.6 \mathrm{eV})$ was employed. The X-ray source was operated at $6 \mathrm{~mA}$ emission current and $12 \mathrm{kV}$ anode bias. The calibration of the spectrometer was performed using $\mathrm{Au}\left(4 \mathrm{f}^{7 / 2}\right), \mathrm{Cu}\left(2 \mathrm{p}^{3 / 2}\right)$ and $\mathrm{Ag}\left(3 \mathrm{~d}^{5 / 2}\right)$ signals. The spot size was an elliptical shape with a long axis of $200 \mu \mathrm{m}$ to make sure that the analysis area was within the wear track. Samples were positioned at $0^{\circ}$ emission angle. Base pressure in the main chamber of the spectrometer was $2 \times 10^{-9}$ mbar. A survey spectrum was acquired in a high-pass energy $(200 \mathrm{eV})$ scanned mode. A narrow scan, used to determine the relative atomic composition as well as for determination of chemical information, was then acquired in a lowpass energy $(20 \mathrm{eV})$ mode. The charging of the specimen

Table 4 MTM test conditions

\begin{tabular}{lc}
\hline Mean (entrainment) speed; $\mathrm{U}=\left(\mathrm{U}_{\text {ball }}+\mathrm{U}_{\text {disc }}\right) / 2$ & $35 \mathrm{~mm} / \mathrm{s}$ \\
\hline Slide-roll-ratio $(\mathrm{SRR}) ; \mathrm{SRR}=100 *\left(\mathrm{U}_{\mathrm{disc}}-\mathrm{U}_{\text {ball }}\right) / \mathrm{U}$ & $100 \%$ \\
Applied load & $34.6 \mathrm{~N}$ (max Hertz \\
& pressure 1.0 \\
Temperature & $\mathrm{GPa})$ \\
Rubbing time & $80^{\circ} \mathrm{C}$ \\
Lambda (minimum EHD film thickness / composite Rq roughness) & $4 \mathrm{~h}$ \\
\end{tabular}


was corrected by referring aliphatic carbon binding energy to $284.8 \mathrm{eV}$ (C 1s signal).

\subsection{Hardness Measurement}

The hardness depth profiles of ion-implanted MTM discs were measured using a nanoindentation method. A Nano Indenter G 200 with a Berkovich tip manufactured by Keysight Technologies was employed. Tests were carried out in the Continuous Stiffness Measurement (CSM) mode, which allows measurement of the contact stiffness at any point along the loading curve [29]. The hardness at each indentation depth was determined by analysing the amplitude and phase response. The frequency and displacement amplitude values were $45 \mathrm{~Hz}$ and $2 \mathrm{~nm}$, respectively. Surface approach velocity was $10 \mathrm{~nm} / \mathrm{s}$. With a load range of $50 \mathrm{mN}$, a target depth of $2 \mu \mathrm{m}$ and a strain rate of $0.01 \mathrm{~s}^{-1}, 25$ points at $25 \mu \mathrm{m}$ intervals was obtained. All measurements were carried out at room temperature.

\section{Results}

\subsection{Effect of Ion Implantation on Tribofilm Formation}

Figure 5 shows the evolution of ZDDP tribofilm thickness on the original and ion-implanted steel balls over $4 \mathrm{~h}$ rubbing time, determined using SLIM. Tribofilms on unimplanted steel gradually grew to approximately $150 \mathrm{~nm}$ over the first $3 \mathrm{~h}$ and then remained stable at this thickness for the remaining hour. Interestingly, implanted $\mathrm{Ni}$ ions considerably promoted tribofilm growth, with tribofilm in this case reaching $150 \mathrm{~nm}$ after only $1 \mathrm{~h}$ of rubbing, and then stabilizing. By contrast, implanted $\mathrm{Mo}$ and $\mathrm{Cr}$ ions deterred tribofilm growth; tribofilms grew much more slowly and reached only

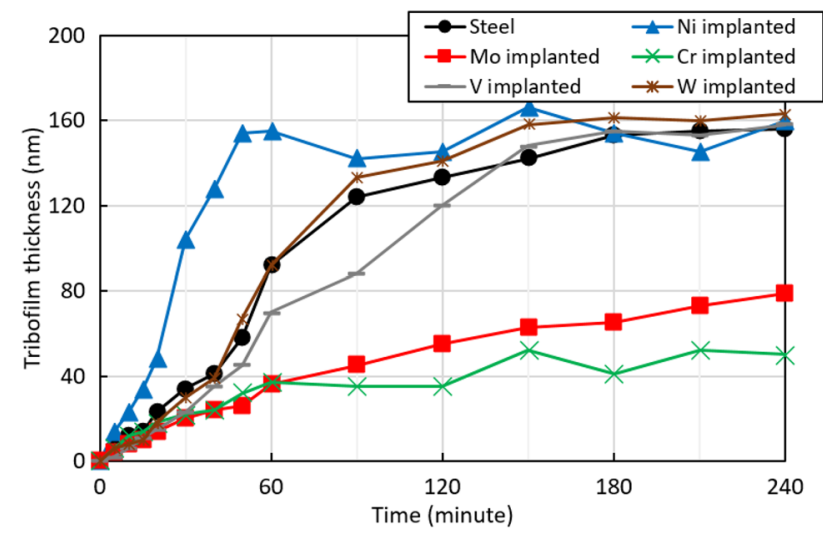

Fig. 5 The evolution of ZDDP tribofilm thickness on the original unimplanted and ion-implanted steel balls during rubbing about $50 \mathrm{~nm}$ at the end of the 4-h tests. V and W implantations did not significantly affect ZDDP tribofilm growth. These results suggest that the chemical composition of steel can have a significant influence on ZDDP tribofilm growth. The observed impact of implanted metals on ZDDP tribofilm growth broadly agrees with a previous study using an esterfunctionalised ashless dithiophosphate additive, except for the behaviour of Mo-implanted steel [19].

Figure 6 shows optical micrographs of tribofilms on the discs and balls after $4 \mathrm{~h}$ rubbing. While ZDDP tribofilms were formed on all specimens, the absence of blue interference colours on Mo- and Cr-implanted steels indicates thinner films in these cases in line with the above SLIM measurements on balls.

Figure 7 shows how MTM friction coefficient versus entrainment speed evolves with rubbing time on steel, $\mathrm{Ni}$ - and Cr-implanted steels. The two characteristic features of friction behaviour with ZDDP tribofilm growth can be seen; (i) a shift of the mixed lubrication region of the friction curves to higher entrainment speed, and (ii) an increase in slow speed boundary friction. For a steel/steel tribopair, friction coefficient increases predominantly in the mixed lubrication regime up to $60 \mathrm{~min}$ rubbing, and then slightly decreases. On Ni-implanted steel, friction coefficient initially increases rapidly across the whole range of lubrication regimes to reach a maximum value after 30 min rubbing. After 30 min rubbing, friction coefficient then decreases to the end of the test. By contrast, with Cr-implanted steel tribopairs, friction coefficient slightly increases, mainly in the mixed lubrication regime, up to $60 \mathrm{~min}$ rubbing, followed by a relatively

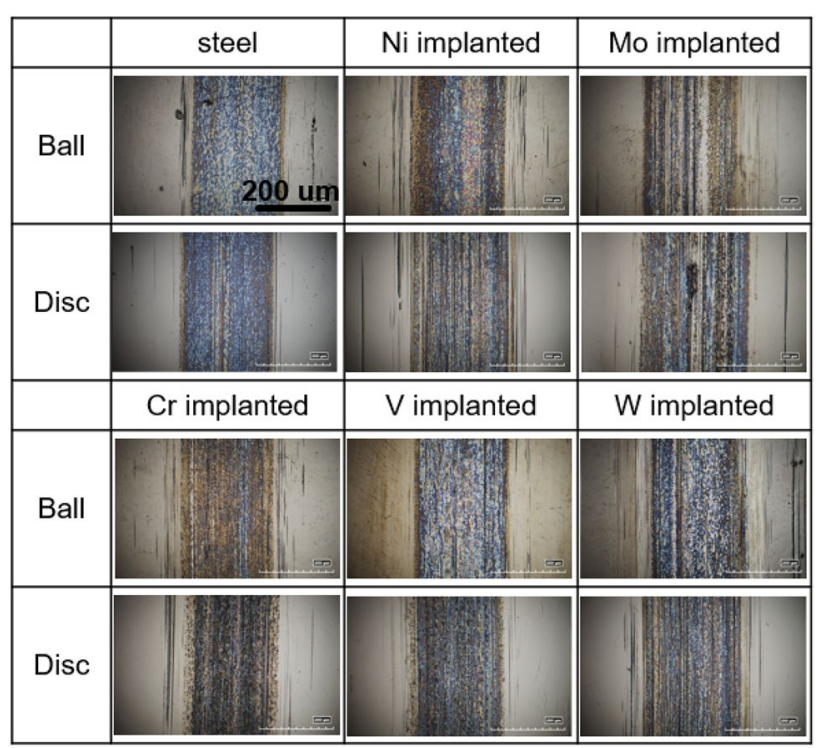

Fig. 6 Optical micrographs of ZDDP tribofilm on the MTM balls and discs after $4 \mathrm{~h}$ rubbing. The scale bar shown in upper left image is applicable to all images 

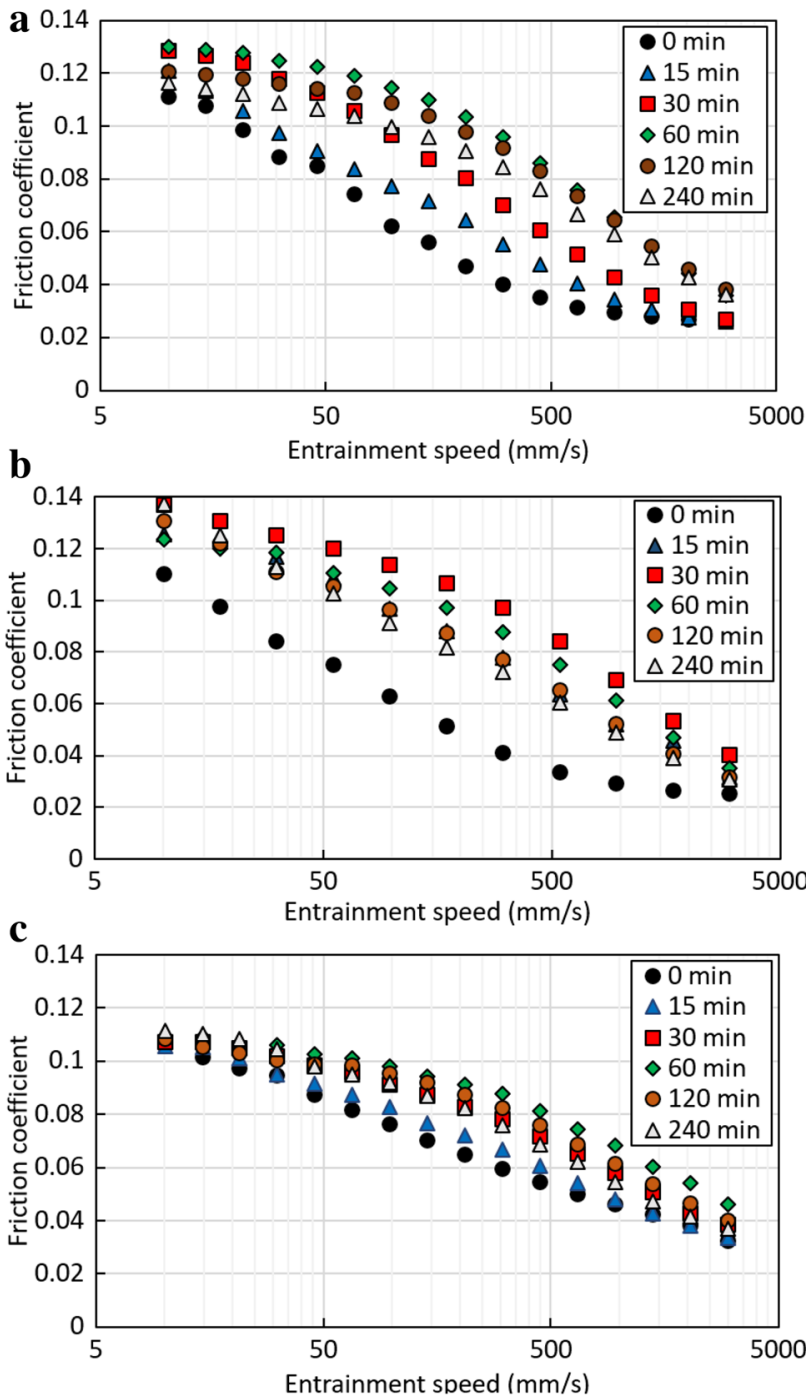

Fig. 7 Evolution of MTM friction coefficient versus entrainment speed curves during $4 \mathrm{~h}$ rubbing on a original 52100 steel, b Niimplanted steel and $\mathbf{c}$ Cr-implanted steel

stable friction coefficient over the whole range of speeds. Recently, Dawczyk et al. [30] proved that the increase in MTM friction in mixed lubrication condition originates from the increase in effective roughness of the rubbing surfaces due to the formation of ZDDP tribofilms. Generally, the trends in increasing friction coefficient followed the tribofilm growth shown in Fig. 4. However, unlike with steel and Cr-implanted steel, tribofilms on Ni-implanted steel might be partially smoothed during rubbing, resulting in the reduction of friction coefficient after $60 \mathrm{~min}$ rubbing.

Figure 8 shows surface profiles of four implanted discs at the end of rubbing tests obtained using a Talysurf stylus profilometer. Profiles are shown before and after EDTA treatment since it is well known that EDTA treatment removes ZDDP tribofilm from surfaces [31]. The results show that there was negligible wear occur of the implanted discs after rubbing. This suggests that implanted metals were present on the surfaces and thus available to affect ZDDP tribofilm formation throughout the tests.

\subsection{Effect of ZDDP Concentration on Tribofilm Formation}

To examine the ability of ZDDP to adsorb on ion-implanted steels, the effect of varying ZDDP concentration on tribofilm formation on (a) steel, (b) Ni-, and (c) Mo- and (d) $\mathrm{Cr}$ implanted steels was studied. Results are shown in Fig. 9. On 52100 steel, tribofilm formation rate increases with $\mathrm{P}$ concentration from 200 to $800 \mathrm{ppm}$, with the $135 \mathrm{~nm}$ and $155 \mathrm{~nm}$ maximum tribofilm thickness, respectively, after $4 \mathrm{~h}$ rubbing. However, $1600 \mathrm{ppm}$ of $\mathrm{P}$ forms a tribofilm at a similar rate and to a similar thickness as $800 \mathrm{ppm} P$. This saturation of tribofilm growth with increased ZDDP concentration was previously observed by Fujita et al. [32]. On Ni-implanted steel, while tribofilm forms faster at $400 \mathrm{ppm} P$ than at $200 \mathrm{ppm} \mathrm{P}$, behaviour at $800 \mathrm{ppm} \mathrm{P}$ is similar to that at $400 \mathrm{ppm}$ P. On Mo- and Cr-implanted steels, tribofilms grew faster and thicker as $\mathrm{P}$ concentration increased from 800 to $1600 \mathrm{ppm}$.

These results show that the concentration of ZDDP above which tribofilm formation saturates varies with the presence of different elements in the surface, being no more than $800 \mathrm{ppm} \mathrm{P}$ for unimplanted steel, $400 \mathrm{ppm} \mathrm{P}$ for Niimplanted steel, and greater than 1600 ppm P with Mo- and Cr-implanted steels. This suggests that ZDDP may adsorb most easily on Ni-implanted steel, and least easily on Moand Cr-implanted steels.

\subsection{Chemical Analysis of Tribofilms}

To understand the effect of ion implantation on ZDDP tribofilm properties, the tribofilms on steel, Ni-, Mo- and $\mathrm{Cr}$ implanted steels were analysed using a range of analytical techniques.

\subsubsection{Elemental Distribution in Tribofilms (STEM-EDX)}

Cross-sections of tribofilms on Ni- and Mo-implanted discs were analysed using STEM-EDX. Tribofilms on $\mathrm{Cr}$ implanted discs were not analysed because of EDX peak overlap between $\mathrm{Cr}$ in the steel disc and implanted $\mathrm{Cr}$. Figure 10 shows the EDX line spectra of tribofilms on $\mathrm{Ni}$ and Mo-implanted steels after $4 \mathrm{~h}$ rubbing tests. The peak intensity was adjusted by scaling to the same phosphorus peak intensity to easily compare the ratio of other elements to phosphorus. Although the tribofilm thickness on 

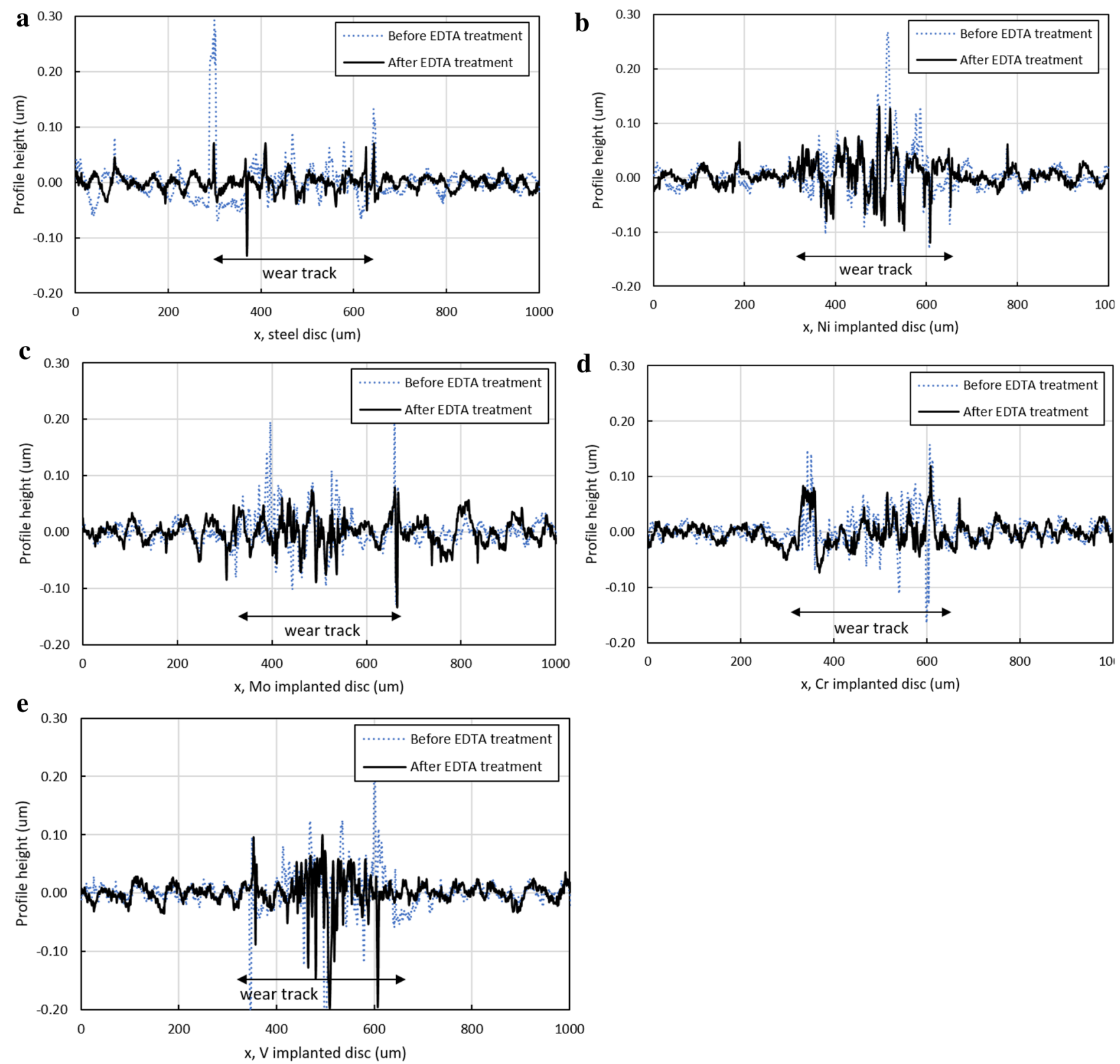

Fig. 8 Surface profiles after rubbing of a steel disc, $\mathbf{b}$ Ni implanted disc, $\mathbf{c}$ Mo-implanted disc, $\mathbf{d}$ Cr implanted disc and e V implanted disc

Ni-implanted disc as shown in Fig. 5 was about $160 \mathrm{~nm}, \mathrm{ca}$. $80 \mathrm{~nm}$ of thickness is observed in the STEM image. It is well known that ZDDP tribofilms have a patchy structure [33], and this discrepancy is probably because the FIB lamella was lifted out from a region with thin tribofilm thickness, such as the edge of a pad structure.Also it has been reported that different techniques give varied thickness values and that SLIM measures a thickness close to the maximum value present [34]. Note that the vertical dashed lines in the figure show only approximate extent of the tribofilm since the exact boundaries are difficult to ascertain in the EDX spectra. Zn and $\mathrm{P}$ were detected in both tribofilms, suggesting the formation of zinc phosphates. The peak of Fe was present in the tribofilm near the steel substrate, and this decreased towards the tribofilm surfaces. This suggests that Fe was transferred into tribofilms from steel substrates. The peaks of implanted $\mathrm{Ni}$ and Mo were clearly detected in both substrates while within the tribofilm, they only appear to be present in the immediate vicinity of the tribofilm-substrate interface and at relatively low concentrations. 


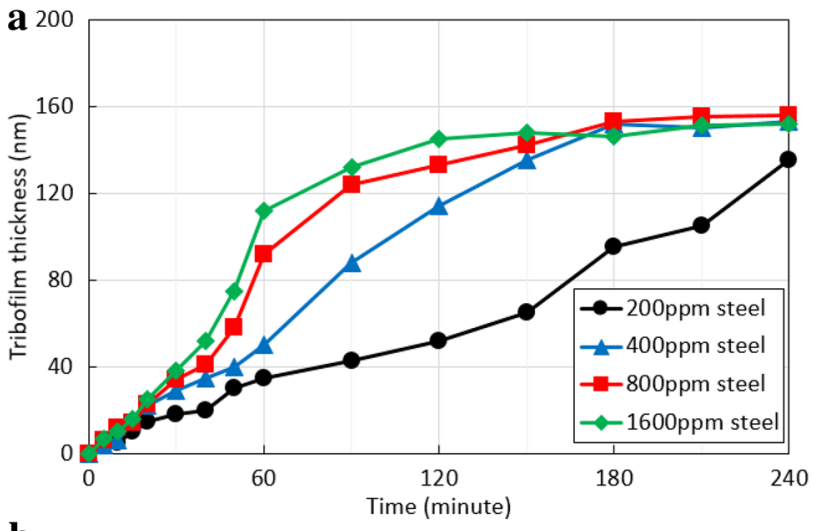

b

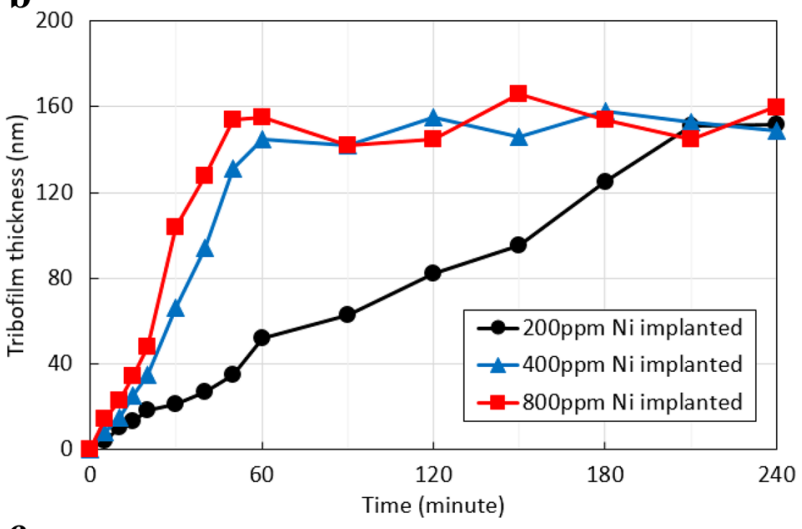

c

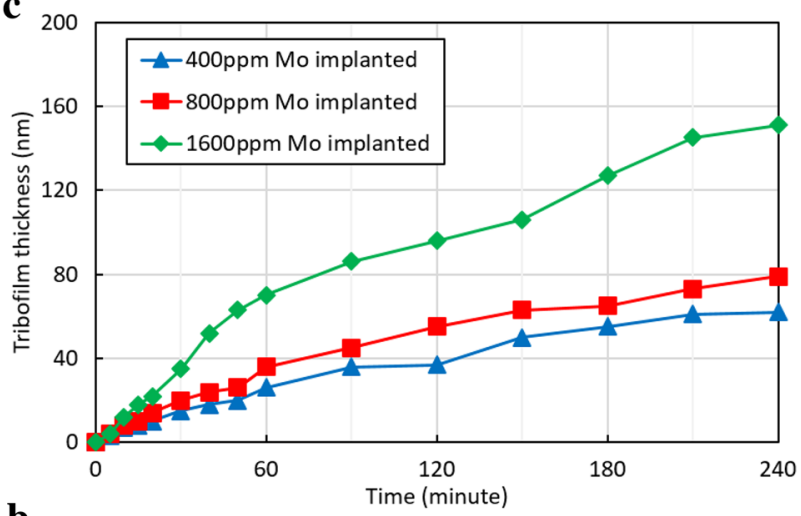

b

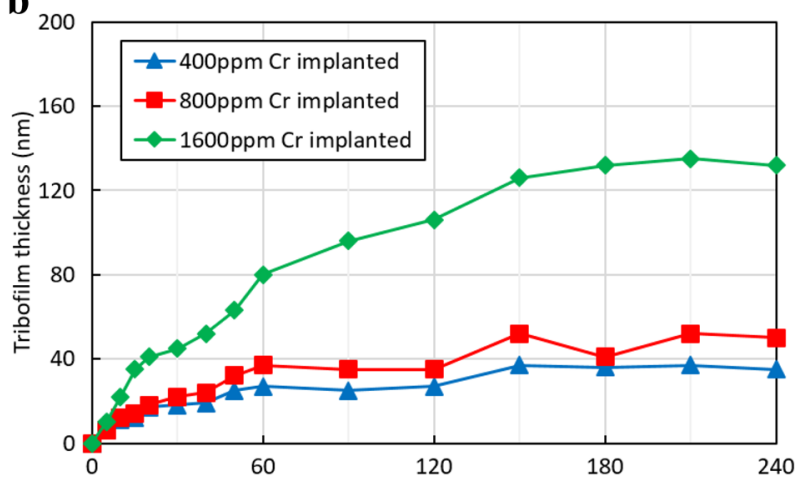

Fig. 9 The effect of ZDDP concentration on tribofilm thickness on a original 52100 steel, b Ni-implanted steel c Mo-implanted steel and d Cr-implanted steel (Note that values quoted in the legend are ppm of $\mathrm{P})$

\subsubsection{Chemical Bonds in Tribofilms (XPS)}

The chemical environment of oxygen in the tribofilm surfaces was analysed using XPS. Figure 11 shows the $\mathrm{O} 1 \mathrm{~s}$ XPS spectra of tribofilms on Ni-, Mo- and Cr-implanted steels after $4 \mathrm{~h}$ rubbing. All spectra were normalized to their maximum peaks to aid comparison. XPS oxygen peaks in phosphate films are generally attributed to non-bridging bond $(\mathrm{NBO} ; \mathrm{P}=\mathrm{O}$ and $\mathrm{P}-\mathrm{O}-\mathrm{M})$ at $531.5 \pm 0.3 \mathrm{eV}$, bridging oxygen $(\mathrm{BO}, \mathrm{P}-\mathrm{O}-\mathrm{P})$ at $532.9 \pm 0.5 \mathrm{eV}$ and oxide at $529.0 \pm 0.3 \mathrm{eV}$ [35-37]. The peak ratio of BN/NBO can be used to estimate the chain length of phosphate in ZDDP tribofilms [31, 32, 34], and this was the same in the tribofilms on each substrate, i.e. $0.38,0.33,0.31$ and 0.33 on steel, $\mathrm{Ni}$-, Mo- and Cr-implanted steels, respectively. Given that XPS signals generally originate from within $c a .10 \mathrm{~nm}$ of the surface, these results suggest that in all four cases the outermost regions of the tribofilms consisted of short chain phosphates such as orthophosphate.

\subsubsection{Crystallinity of Tribofilms (TEM)}

The nanocrystallisation of phosphate structure was investigated using TEM. Figure 12 shows TEM images of cross sections of ZDDP tribofilms on Ni- and Mo-implanted steels after $4 \mathrm{~h}$ rubbing, together with FFT images captured from a white square. Given the lattice fringes and FFT spots, both tribofilms were crystalline both near the substrate and close to the surface. These results suggest that the ZDDP tribofilms formed on these specimens are nanocrystalline throughout. This has previously been observed for secondary ZDDPs [28].

\section{Discussion}

The results presented here indicate that the ion implantation of relatively low concentrations of selected transition metals into standard through-hardened bearing steel can considerably affect ZDDP tribofilm formation. In particular, implantation of Ni greatly increases the rate of ZDDP tribofilm growth, while $\mathrm{Mo}$ and $\mathrm{Cr}$ reduce the rate of growth and thickness of film formed. Unfortunately, the effect of ion implantation on the hardness of the near-surface could not measured. However, negligible wear occurred on any implanted disc after rubbing, as shown in Fig. 8. In addition, friction evolution shown in Fig. 7 is mainly affected by ZDDP tribofilm formation. These suggest that any effect of hardness from implanted ions on tribological performance is unlikely to be significant and that the differences in tribofilm film formation are most likely to be due to the differences of surface chemical composition resulting from implantion; i.e. 
Fig. 10 STEM images and EDX line profiles of the tribofilms on Ni-and Mo-implanted steels

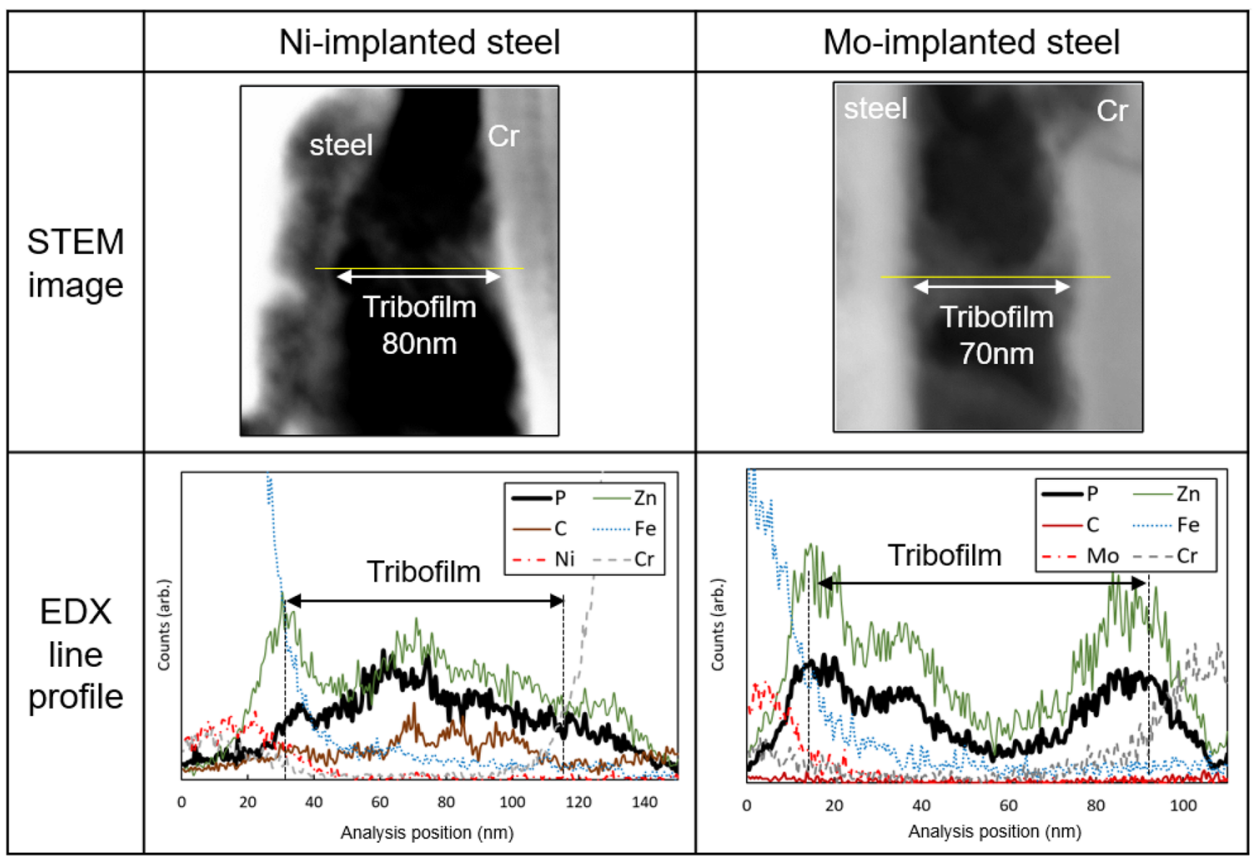

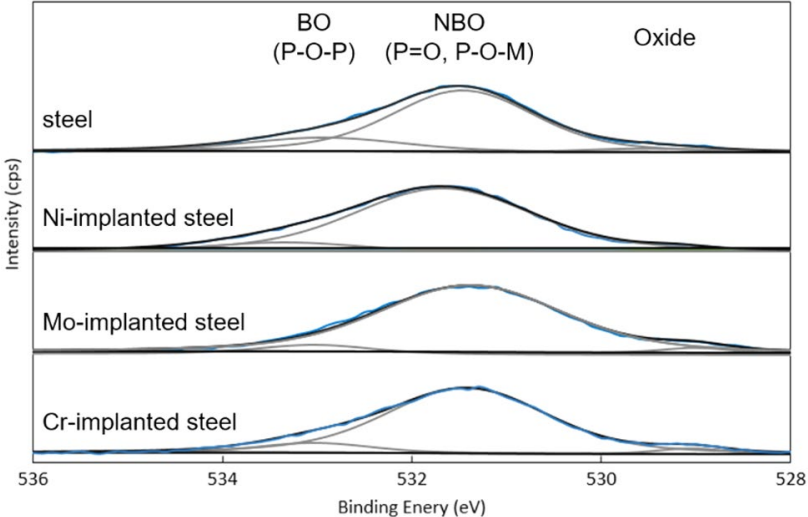

Fig. 11 O s XPS spectra of ZDDP tribofilms on steel, Ni-, Mo-and Cr-implanted steels

ZDDP tribofilm formation is dependent on surface chemical composition. It is, therefore, of interest to consider how ion implantation might influence each of the main chemical stages of ZDDP tribofilm formation. These stages are (i) adsorption of ZDDP molecules; (ii) polymerization to polyphosphate; (iii) depolymerization to phosphate [33].

\subsection{Surface adsorption}

Diffusion to and adsorption of ZDDP molecules or moieties derived from ZDDP onto the surface must be the first stage of tribofilm formation on a rubbing surface. While the presence of $\mathrm{Fe}$ is not needed for the growth of ZDDP tribofilm [9], Yamaguchi et al. [35, 36] showed that ZDDP

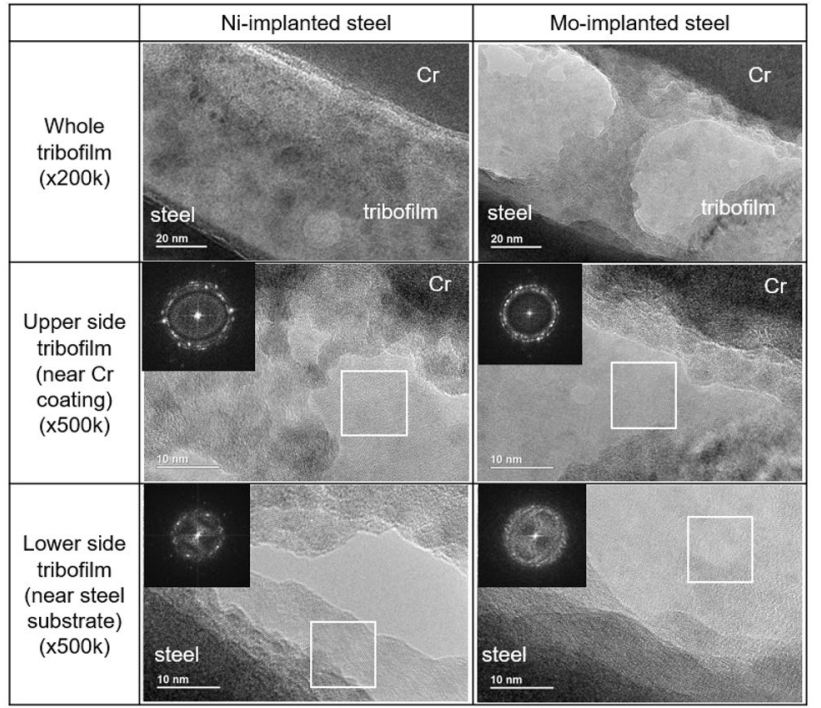

Fig. 12 TEM images and FFTs of ZDDP tribofilms on Ni-and Moimplanted steels

molecules adsorb on Fe via the sulphur atom of the $\mathrm{P}=\mathrm{S}$ bond, suggesting Fe can play an important role in promoting tribofilm formation on steel by acting as an adsorption site for ZDDP molecules. As the ZDDP concentration was found to control tribofilm formation rate to a different extent between unimplanted steel and Ni-, Mo- and Cr-implanted steels in this study, it is probable that the implanted ions affected ZDDP adsorption behaviour. It is quite likely that some metals, but not all, can act as strong adsorption sites in a similar fashion to $\mathrm{Fe}$ in steel. Given the results in Fig. 5, Ni 
ions may promote ZDDP adsorption more than $\mathrm{Cr}$ and Mo. Dacre et al. [41] studied ZDDP adsorption on steel surfaces containing different $\mathrm{Cr}$ concentrations and found that $\mathrm{Cr}$ deterred ZDDP adsorption. The authors suggested that the presence of $\mathrm{Cr}$ on a surface may decrease the reactivity of surfaces. It is possible that Mo ions may behave in a similar way to $\mathrm{Cr}$ ions in decreasing the adsorption of ZDDP.

The tribofilm growth rate was fastest for $\mathrm{Ni}$-implanted steel, followed by unimplanted 52100 steel and the slowest for Cr- and Mo-implanted steels. Studt [42] and our previous study [43] suggested that ZDDP adsorption may be influenced by the reactivity of surfaces of both ferrous and non-ferrous materials. As discussed previously [43], ionicity may be an influential factor. As shown in Fig. 3, the chemical state of implanted ions on steels are both metal oxide and pure metal. Jones et al. [44] showed that ZDDP adsorbed well on iron oxide and cast iron, but relatively poorly on pure iron, suggesting that ZDDP may adsorb more easily on metal oxides. Therefore, the order of estimated ionicity of metal oxides in this study may be listed as follows, based on Fig. 3 and Table 1 of a study by Lenglet [45]:

$\mathrm{NiO}>\mathrm{Fe}_{2} \mathrm{O}_{3}>\mathrm{Cr}_{2} \mathrm{O}_{3}, \mathrm{MoO}_{3}$

In the case of $\mathrm{Mo}, \mathrm{MoO}_{3}$ was selected because the strongest peak was $\mathrm{Mo}^{6+}$. This follows the observed trend in the tribofilm growth rates in Fig. 5. Therefore, it is likely that a surface with high ionicity may provide a polar surface with high surface energy, resulting in the increase of adsorption of polar ZDDP molecules. For better understanding of this phenomenon, ZDDP adsorption behaviour might be investigated using metal oxide sensors in a quartz crystal microbalance (QCM).

\subsection{Polymerization and Depolymerization}

After adsorption, an intermolecular reaction between dialkyl dithiophosphate (or dithioalkyl phosphate) species is believed to lead to rapid polymerization to form long chain polyphosphates, followed by slower depolymerization of the long chain polyphosphates to short chain phosphates by loss of thioalkyl or alkoxy groups [34, 42]. This depolymerization increases anionic charge in phosphates which is balanced by cations such as Zn cations in ZDDP or Fe cations which may diffuse into the tribofilm from the steel substrate, resulting in the formation of iron phosphates [47]. In principle, the implanted metal ions of this study might also diffuse into the tribofilm and participate in depolymerization from polyphosphate to phosphate. However, although this mechanism may play a role in ZDDP film formation in this study, its relative significance is not entirely clear from the present results: STEM-EDX analysis only detected relatively low concentrations of Mo and $\mathrm{Ni}$ ions in the lower regions of the tribofilm, near the steel substrate, but not throughout the tribofilm despite the fact that almost full depolymerization of the films occurred.

It is of interest to compare the findings of this study with other work that looked at the effect of ion implantation of metals on tribofilm formation. Yang et al. [15-17] studied the effect of implantation of $\mathrm{Ni}$, Mo and $\mathrm{Al}$ ions into pure $\mathrm{Fe}$ on friction and wear. In the absence of ZDDP they found that less wear occurred on the implanted specimens in base oil than on pure Fe and suggested that ion implantation might increase surface residual compressive stress and microhardness, resulting in less wear. They also found that all three implanted metals deterred the formation of an antiwear tribofilm by ZDDP, as measured by surface $S$ and $Z n$ content after rubbing. It should be noted that their study used pure sliding, reciprocating contact at room temperature at relatively low load and found very little P on the rubbed surfaces, suggesting that either the temperature or, because of the low hardness of pure iron, the contact pressure, was too low for polyphosphate tribofilm formation.

Pagkalis explored the influence of ion implantation of metals into AISI 52100 bearing steel on tribofilm formation with acid and ester based ashless S/P antiwear additives [19], and found that the influence of specific ions may be even greater on the formation of ashless tribofilms than on ZDDP films shown here. He employed MTM-SLIM under very similar conditions to the current work, the main differences being the use of a PAO/ester base oil blend to ensure full solubility of the ashless additive studied, and much longer test times. His results show both similarities to and differences from the current study. As in the current work, implantation of $\mathrm{Cr}$ reduced ashless tribofilm formation while Ni implantation resulted in very rapid film growth with ester based ashless additive. However, Pagkalis found that Mo-implantation resulted in an increase in film thickness with ashless additives, while in the current study it was detrimental to ZDDP tribofilm formation. Unlike for ZDDP that contains Zn, with ashless additives the formation of a thick tribofilm requires the generation of metal cations from the surface to form a phosphate, so differences between implantation metals may reflect, at least in part, differences in their release from the rubbing surfaces rather, as in the current study, differences in adsorption behaviour.

Overall, the observations discussed here suggest that ZDDP tribofilm thickness and growth rate vary with the chemical composition of the steel substrate and in particular, the metal ions present. This has practical implications in optimizing both lubricant formulation and the chemical compositions of rubbing materials to control antiwear behaviour of a given mechanical component. 


\section{Conclusions}

ZDDP tribofilm formation on $\mathrm{Ni}, \mathrm{Mo}, \mathrm{Cr}, \mathrm{V}$ and $\mathrm{W}$ ionimplanted AISI 52100 bearing steel has been studied using an MTM ball on disc tribometer with post-test tribofilm analysis using STEM-EDX, XPS and TEM. Key conclusions are as follows:

- The implantation of different metal ions into steel surfaces results in variations in the rate of ZDDP tribofilm growth; $\mathrm{Ni}$ ions promote tribofilm growth whereas Mo and $\mathrm{Cr}$ ions deter tribofilm growth. The implantation of $\mathrm{V}$ and $\mathrm{W}$ ions does not significantly affect ZDDP tribofilm formation.

- The rate of tribofilm growth on steel, $\mathrm{Ni}-$, $\mathrm{Mo}-$ and $\mathrm{Cr}-$ implanted steels varies with ZDDP concentration up to a critical concentration above which there is no further change. This critical, saturating concentration depends on the type of metal ion implanted and, for the ZDDP studied here, is no more than $800 \mathrm{ppm} P$ for unimplanted AISI 52100 steel, 400 ppm P for Ni-implanted steel and more than 1600 ppm for Cr- and Mo-implanted steels. This suggests that the observed variation in ZDDP tribofilm formation with different implanted ions may originate from differences in surface reactivity, and thus the ease of adsorption of ZDDP on the surfaces, resulting from different ion implantation.

- Fe was clearly detected in the ZDDP tribofilms using STEM-EDX analysis. Possible presence of $\mathrm{Ni}$ and Mo in relatively small concentrations was detected near the substrate-tribofilm interface but not higher up in the respective tribofilms. Therefore, their potential role in depolymerization stage of tribofilm formation in not entirely clear in the present results.

- XPS analysis showed that tribofilms near the outermost surface on steel, Ni-, Mo- and Cr-implanted steels mainly consisted of short chain phosphates and orthophosphates. TEM of FIB-extracted lamellae also showed that the tribofilms on Ni- and Mo-implanted steels were predominantly nanocrystalline throughout their thickness.

- The fact that alloying metals in steels affect tribofilm formation has practical implications for optimizing lubricants and the composition of substrate surfaces to protect components from wear.

\footnotetext{
Acknowledgements The authors would like to thank Shell Lubricants Japan K.K. for supply of the base oils and additives for this study. The authors also wish to acknowledge the support of the Henry Royce Institute through the Royce PhD Equipment Access Scheme enabling access to Agilent Nanoindentation G200 in UKAEA facilities at Royce@ CCFE; EPSRC Grant Number EP/R00661X/1.
}

Open Access This article is licensed under a Creative Commons Attribution 4.0 International License, which permits use, sharing, adaptation, distribution and reproduction in any medium or format, as long as you give appropriate credit to the original author(s) and the source, provide a link to the Creative Commons licence, and indicate if changes were made. The images or other third party material in this article are included in the article's Creative Commons licence, unless indicated otherwise in a credit line to the material. If material is not included in the article's Creative Commons licence and your intended use is not permitted by statutory regulation or exceeds the permitted use, you will need to obtain permission directly from the copyright holder. To view a copy of this licence, visit http://creativecommons.org/licenses/by/4.0/.

\section{References}

1. Li, Y.R., Pereira, G., Kasrai, M., Norton, P.R.: The effect of steel hardness on the performance of ZDDP antiwear films: a multitechnique approach. Tribol. Lett. 29, 201-211 (2008)

2. Sheasby, J.S., Caughlin, T.A., Mackwood, W.A.: The effect of steel hardness on the performance of antiwear additives. Wear 201, 209-216 (1996)

3. Lin, Y.C., So, H.: Limitations on use of ZDDP as an antiwear additive in boundary lubrication. Tribol. Int. 37, 25-33 (2004)

4. Kubiak, K.J., Mathia, T.G., Bigerelle, M.: Influence of roughness on ZDDP tribofilm formation in boundary lubricated fretting. Tribol. - Mater. Surfaces Interfaces. 6, 182-188 (2012)

5. Ji, H., Nicholls, M.A., Norton, P.R., Kasrai, M., Capehart, T.W., Perry, T.A., Cheng, Y.T.: Zinc-dialkyl-dithiophosphate antiwear films: dependence on contact pressure and sliding speed. Wear 258, 789-799 (2005)

6. Brizmer, V., Matta, C., Nedelcu, I., Morales-Espejel, G.E.: The Influence of tribolayer formation on tribological performance of rolling/sliding contacts. Tribol. Lett. 65, 1-18 (2017)

7. Jelita Rydel, J., Pagkalis, K., Kadiric, A., Rivera-Díaz-delCastillo, P.E.J.: The correlation between ZDDP tribofilm morphology and the microstructure of steel. Tribol. Int. 113, 13-25 (2017)

8. Pagkalis, K., Spikes, H., Jelita-Rydel, J., Ingram, M., Kadiric, A.: The influence of steel composition on the formation and effectiveness of anti-wear films in tribological comtacts, Tribol. Lett. 2021

9. Gosvami, N.N., Lahouij, I., Ma, J., Carpick, R.W.: Nanoscale in situ study of ZDDP tribofilm growth at aluminum-based interfaces using atomic force microscopy. Tribol. Int. 143, 106075 (2020)

10. Iwaki, M.: Tribological properties of ion-implanted steels. Mater. Sci. Eng. 90, 263-271 (1987)

11. Peng, D.Q., Bai, X.D., Chen, X.W., Zhou, Q.G., Liu, X.Y., Yu, R.H., Deng, P.Y.: Effect of Ni ion implantation on corrosion behavior of zircaloy-4 in $0.5 \mathrm{M} \mathrm{H}_{2} \mathrm{SO}_{4}$. J. Electrochem. Soc. 151, 491 (2004)

12. Smidt, F.A.: Recent advances in the application of ion implantation to corrosion and wear protection. Nucl. Instrum. Methods Phys. Res. Sect. B. 10, 532-538 (1985)

13. Akbas, N., Oztarhan, A., Monteiro, O.R., Brown, I.G.: Investigation on the tribology of $\mathrm{Zr}$ ion implanted tool steel. Wear 252, 540-545 (2002)

14. Li, M., Knystautas, É.J., Krishnadev, M.: Enhanced microhardness of four modern steels following nitrogen ion implantation. Surf. Coat. Technol. 138, 220-228 (2001)

15. Yang, D., Zhou, J., Xue, Q.: Tribochemical behavior of Ni ion implanted pure iron lubricated with ZDDP as an additive. Wear 199, 60-65 (1996) 
16. Yang, D.H., Xue, Q.J., Zhang, X.S., Wang, H.Q., Lin, W.L., Ding, X.J.: The influence of ion-implanted Mo on the tribological behavior of iron lubricated with oil containing antiwear additives. Wear 173, 129-135 (1994)

17. Yang, D., Zhou, J., Xue, Q.: Study of the tribochemical behavior of $\mathrm{Al}$ ion-implanted pure iron lubricated with ZDDP. Surf. Coat. Technol. 102, 223-232 (1998)

18. Warren, C.D., Wert, J.J.: The influence of implanted transition metal ions on the adhesive wear of iron. Wear 134, 149-164 (1989)

19. Pagkalis, K.: Influence of steel composition on the formation and effectiveness of lubricant boundary layers in tribological contacts. PhD Thesis, Imp. Coll. London. 2017.

20. Saha, R., Nix, W.D.: Effects of the substrate on the determination of thin film mechanical properties by nanoindentation. Acta Mater. 50, 23-38 (2002)

21. Notthoff, C., Winterer, M., Beckel, A., Geller, M., Heindl, J.: Spatial high resolution energy dispersive X-ray spectroscopy on thin lamellas. Ultramicroscopy 129, 30-35 (2013)

22. Kim, K.S., Winograd, N.: X-ray photoelectron spectroscopic studies of nickel-oxygen surfaces using oxygen and argon ionbombardment. Surf. Sci. 43, 625-643 (1974)

23. Biesinger, M.C., Payne, B.P., Grosvenor, A.P., Lau, L.W.M., Gerson, A.R., Smart, R.S.C.: Resolving surface chemical states in XPS analysis of first row transition metals, oxides and hydroxides: Cr, Mn, Fe, Co and Ni. Appl. Surf. Sci. 257, 2717-2730 (2011)

24. Kocijan, A., Milošev, I., Pihlar, B.: Cobalt-based alloys for orthopaedic applications studied by electrochemical and XPS analysis. J. Mater. Sci. Mater. Med. 15, 643-650 (2004)

25. Baltrusaitis, J., Mendoza-sanchez, B., Fernandez, V., Veenstra, R., Dukstiene, N., Roberts, A., Fairley, N.: Applied surface science generalized molybdenum oxide surface chemical state XPS determination via informed amorphous sample model. Appl. Surf. Sci. 326, 151-161 (2015)

26. Mendialdua, J., Casanova, R., Barbaux, Y.: XPS studies of $\mathrm{V}_{2} \mathrm{O}_{5}$, $\mathrm{V}_{6} \mathrm{O}_{13}, \mathrm{VO}_{2}$ and $\mathrm{V}_{2} \mathrm{O}_{3}$. J. Electron. Spectros. Relat. Phenomena. 71, 249-261 (1995)

27. Dawczyk, J., Ware, E., Ardakani, M., Russo, J., Spikes, H.: Use of FIB to study ZDDP tribofilms. Tribol. Lett. 66, 1-8 (2018)

28. Ueda, M., Kadiric, A., Spikes, H.A.: On the crystallinity and durability of ZDDP tribofilm. Tribol. Lett. 67, 1-13 (2019)

29. Li, X., Bhushan, B.: A review of nanoindentation continuous stiffness measurement technique and its applications. Mater. Charact. 48, 11-36 (2002)

30. Dawczyk, J., Morgan, N., Russo, J., Spikes, H.: Film thickness and friction of ZDDP tribofilms. Tribol. Lett. 67, 34 (2019)

31. Benedet, J., Green, J.H., Lamb, G.D., Spikes, H.A.: Spurious mild wear measurement using white light interference microscopy in the presence of antiwear films. Tribol. Trans. 52, 841-846 (2009)

32. Fujita, H., Glovnea, R.P., Spikes, H.A.: Study of zinc dialkydithiophosphate antiwear film formation and removal processes, part I: experimental. Tribol. Trans. 48, 558-566 (2005)
33. Spikes, H.: The history and mechanisms of ZDDP. Tribol. Lett. 17, 469-489 (2004)

34. Dawczyk, J.U.: The Effect of Organic Friction Modifiers on ZDDP Tribofilm. PhD Thesis, Imp. Coll. London. 2018.

35. Crobu, M., Rossi, A., Mangolini, F., Spencer, N.D.: Chain-lengthidentification strategy in zinc polyphosphate glasses by means of XPS and ToF-SIMS. Anal. Bioanal. Chem. 403, 1415-1432 (2012)

36. Crobu, M., Rossi, A., Mangolini, F., Spencer, N.D.: Tribochemistry of bulk zinc metaphosphate glasses. Tribol. Lett. 39, 121-134 (2010)

37. Eglin, M., Rossi, A., Spencer, N.D.: X-ray photoelectron spectroscopy analysis of tribostressed samples in the presence of $\mathrm{ZnDTP}$ : a combinatorial approach. Tribol. Lett. 15, 199-209 (2003)

38. Heuberger, R., Rossi, A., Spencer, N.D.: XPS study of the influence of temperature on ZnDTP tribofilm composition. Tribol. Lett. 25, 185-196 (2007)

39. Fuller, M., Yin, Z., Kasrai, M., Bancroft, G.M., Yamaguchi, E.S., Ryason, P.R., Willermet, P.A., Tan, K.H.: Chemical characterization of chemical and thermal films erated from neutral and basic ZDDPs using X-ray absorption spectroscopy. Tribol. Int. 30, 305-315 (1997)

40. Yamaguchi, E.S., Ryason, P.R.: Inelastic electron tunneling spectra of lubricant oil additives on native aluminum oxide surfaces. Tribol. Trans. 36, 367-374 (1993)

41. Dacre, B., Bovington, C.H.: The effect of metal composition on the adsorption of zinc di-isopropyldithiophosphate. ASLE Trans. 26, 333-343 (1983)

42. Studt, P.: Boundary lubrication: adsorption of oil additives on steel and ceramic surfaces and its influence on friction and wear. Tribol. Int. 22, 111-119 (1989)

43. Ueda, M., Kadiric, A., Spikes, H.: ZDDP tribofilm formation on non-ferrous surfaces. Tribol. Online. 15, 318-331 (2020)

44. Jones, W.G., Pope, M.I.: The heats of adsorption of zinc di n-alkyl dithio phosphates onto pure iron, cast iron and ferric oxide surfaces. Thermochim. Acta. 130, 141-148 (1988)

45. Lenglet, M.: Iono-covalent character of the metal-oxygen bonds in oxides: a comparison of experimental and theoretical data. Act. Passiv. Electron. Components. 27, 1-60 (2004)

46. Jones, R.B., Coy, R.C.: The chemistry of the thermal degradation of zinc dialkyldithiophosphate additives. ASLE Trans. 24, 91-97 (1981)

47. Mourhatch, R., Aswath, P.B.: Tribological behavior and nature of tribofilms generated from fluorinated ZDDP in comparison to ZDDP under extreme pressure conditions Part 1: structure and chemistry of tribofilms. Tribol. Int. 44, 187-200 (2011)

Publisher's Note Springer Nature remains neutral with regard to jurisdictional claims in published maps and institutional affiliations. 